\title{
A RANDOMISED CONTROLLED TRIAL BETWEEN SOLID SIGN INTRAMEDULLARY NAIL AND HOLLOW PITKAR NAIL IN DISPLACED SHAFT FRACTURES IN ADULT TIBIA
}

Sathis Chandran $P^{1}$

${ }_{1}^{1}$ Associate Professor, Department of Orthopaedics, Kannur Medical College, Anjarakandy, Kannur, Kerala.

\section{ABSTRACT}

\section{BACKGROUND}

Interlocking nailing is the standard accepted method of treatment for displaced shaft fractures in adult tibia. The fractures of Tibia shaft present differently depending upon the site, in their orientation, degree of comminution and whether it is compound or otherwise. There are various designs of tibia nails available to choose for the surgical treatment of tibia fractures. It is difficult to procure all of them in any given hospital. The Institute where the present study is conducted is equipped with two different types of Tibia nails. One among them is an Indian manufactured nail marketed by (PITKAR), which is a hollow nail. The other one is an American made solid nail called Surgical Implant Generation Network (SIGN) nail. Both are different in their designing and manufacturing techniques. Hence, a comparative clinical study using both these nails was attempted.

Aim of the Study- To study and suggest as to which type of nail among the Hollow or Solid Tibia nails is suitable depending on the type of fracture in shaft of Tibia.

\section{MATERIALS AND METHODS}

72 adult patients with Tibia shaft fractures treated with Intramedullary Nailing (IMN) were divided into 2 groups. Group A patients treated SIGN Tibia solid IMA (41). Group B patients treated using (PITKAR) Indian Hollow IMN (31). Clinical data and final results were analysed to compare the efficacy of two types of commonly used IMN nails.

\section{RESULTS}

Out of 72 patients 56 were males and 16 females; 36 patients were aged 34 - 49 years (50\%), 22 were 18 to 33 years (30.55\%); 35 were operated within 24 hours (48.61\%), 16 within 72 hours (22.22\%). Excellent results in 18 of the Group A (25\%) and 15 of B (20.83\%); 11 of the Group A (15.27\%) were Good and 08 of the Group B (11.11\%); 10 patients showed fair results in Group A $(13.88 \%)$ and 06 of Group B (8.33\%).

\section{CONCLUSION}

Intramedullary nailing for fractures of shaft of Tibia with Solid (SIGN) or Hollow (PITKAR) nailing gives unequivocal results with identical clinical parameters used pre-operatively and post-operatively. The complication rate is lower with both the methods. The Chi square statistic was 0.3646 . The $\mathrm{p}$-value was 0.9474 . The result was not significant at $\mathrm{p}<0.05$.

\section{KEYWORDS}

Open Fracture Tibia, Intramedullary Nail, Solid SIGN Nail, Hollow Nail, Rehabilitation.

HOW TO CITE THIS ARTICLE: Chandran SP. A randomised controlled trial between solid SIGN intramedullary nail and hollow PITKAR nail in displaced shaft fractures in adult tibia. J. Evolution Med. Dent. Sci. 2017;6(34):2801-2807, DOI: 10.14260/Jemds/2017/604

\section{BACKGROUND}

Intramedullary fixation has become the standard treatment of both femoral and tibia shaft fractures.(1) Intramedullary Nail (IMN) functions as an internal splint that allows secondary fracture healing. Solid nails come in various thicknesses and lengths and because it is solid and strong enough to afford slots rather than holes.(2) There is a proximal hole and a slot proximally, while there are two slots at the distal portion. There is a jig for both proximal and distal locking avoiding the necessity of $\mathrm{C}$ arm use.(2) There is a smooth 9 degree apex posterior Herzog bend proximally;

Financial or Other, Competing Interest: None.

Submission 21-03-2017, Peer Review 14-04-2017,

Acceptance 20-04-2017, Published 27-04-2017.

Corresponding Author:

Dr. Sathis Chandran P,

Associate Professor,

Department of Orthopaedics,

Kannur Medical College,

Anjarakandy, Kannur, Kerala

E-mail: sathisv@gmail.com

DOI: $10.14260 /$ jemds $/ 2017 / 604$
$5 \mathrm{~cm}$ from the proximal and a 1.5 degree apex posterior bend at the distal end and orientation of distal locking slots are anteroposterior.(1,2) The axial and rotational stability of the conventional hollow interlocking nails depends primarily on the locking screws.(3) Hollow nails allow use of a guidewire, which can be passed through initially before passing the nail. This also comes in various lengths and thicknesses. The chances of deformation in the nail while introduction are more because of hollow nature, so distal locking has to be by freehand using $\mathrm{C}$ arm.(4) There is jig only for proximal locking available. There is a Herzog bend $6.5 \mathrm{~cm}$ from proximal end and is of 15 degrees and the rest of the nail is straight.(4) The orientation of distal locking holes is mediolateral in PITKAR nails. SIGN was established in 1999 as a humanitarian, nonprofit corporation to provide improved health care and appropriate orthopaedic treatment of fractures at little or no cost to people in need throughout the developing world.(5) Majority of these nails are inserted without reaming and the use of an image intensifier. In developed countries, in part because of easy access to intra-operative fluoroscopy, most commercially available tibial nails are hollow. These are cannulated systems that can be used for reamed and 
unreamed techniques, enabling nail insertion over a guidewire.(6,7) Few studies have compared the biomechanical characteristics of solid and hollow nails.(8) More recent series have demonstrated union rates of $90 \%$ for tibia fractures treated with SIGN nails, $(9,10)$ similar to union rates reported for reamed hollow nails.(11,12) However, despite its widespread use, there is no published data on the biomechanical properties of the SIGN nail. The present study is aimed to compare the usage of SIGN tibial nail and a standard hollow tibial IMN system.

\section{MATERIALS AND METHODS \\ Study Design}

A Prospective Randomised controlled trial conducted over a period of 1 year.

The present study was conducted in patients attending the trauma unit of tertiary teaching hospital attached to Kannur Medical College, Anjarakandy, Kannur. The study period was from Jan 2013 to Dec 2014. All the 72 adult patients with Tibia shaft fractures who are treated with intramedullary nailing were included in the study. Patients were divided into 2 groups by using randomisation method from online randomisation available at Statsdirect.com. Group A patients were treated using SIGN tibia solid intramedullary nails; 42 patients. Group B patients were treated by using (PITKAR) Indian Hollow intramedullary tibia nails; 30 patients. Ethical Committee cleared consent was taken from all the patients. The Institutional Ethical Committee clearance was obtained before starting the study.

\section{Inclusion Criteria}

1. Patients with fresh fractures, 2. Adult patients aged above 18 and below 65 years, 3. Patients with simple fracture shaft of Tibia, 4. Patients with compound type of fractures I, II, IIIA as per Gustilo's classification,(12) 4 . Fractures at least $7 \mathrm{~cm}$ from the knee and ankle joints.

\section{Exclusion Criteria}

1. Patients aged below 18 years and above 65 years, 2 . Revision cases of fracture tibia, 3. Pathological fractures, 4. Fractures in children, 5. Patients with associated head injuries, abdominal trauma or chest trauma. Pre-operatively, the length and width of the nail were calculated provisionally. Appropriate sized nail was assembled to the Distal Locking Target Device to adjust distal locking screws position for SIGN nails. The operative procedure consisted of the procedure undertaken under general or spinal anaesthesia; position of the patient was supine on regular operation table with knee flexed to $90^{\circ}$. Image intensifier to access the reduction, check position of guidewire and nail for locking were used. Insertion point aligned with medullary cavity made after giving midline incision at tibial plateau splitting patellar tendon. Fracture reduction was done and guidewire passed to distal fragment with the help of image intensifier for Hollow nails. Both the proximal and distal fragments were reamed. The nail was inserted through the entry portal over the guidewire in the medullary canal and position and length of nail was checked with image intensifier. Proximal locking was done with the help of insertion handle, while as distal locking was done with free hand technique. Post-operatively,
Quadriceps exercises, knee bending exercises and ankle movements were started soon after the patient was comfortable and was progressed to partial weight bearing and full weight bearing according to the tolerance of the patient, fracture pattern, associated injuries and progress of healing of fracture. Full weight bearing was started when there was radiological and clinical evidence of healed fractures. Patients were followed every 4 weeks till a minimum period of 2 years.

\section{Evaluation of Results \\ Excellent}

Normal function. No post-operative complication. No remaining symptoms.

\section{Good}

Sound bony union in normal position and alignment without shortening, minor post-operative complication, occasional discomfort during certain activities like squatting and some joint activities.

\section{Fair}

Prolonged discomfort, bony union in good position but with shortening of more than $2 \mathrm{cms}$, nail bending, angulations more than $10^{\circ}$.

\section{Poor}

Moderate loss of function, deep infection, shortening more than $2 \mathrm{cms}$, fracture of nail.

\section{Statistical Tools Used}

Data collected was analysed by quantitative discrete variable method. The end results were of both groups compared using Chi-Square Calculator $5 \times 5$ contingency table to calculate the $p$ value ( $p$ taken as significant at 0.05 ).

\section{RESULTS}

72 adult patients attending the Department of Orthopaedics of a tertiary teaching hospital in north Kerala attached to Kannur Medical College were included in the present study. The study period was between Jan 2013 and Dec 2015. All the patients were involved in motor vehicle accidents. The age group of the patients in the study ranged from 18 years to 62 with a mean age of $36.40 \pm 5.20$. Among the 72 patients, 56 were males and the remaining 16 patients were females. Patients were divided into 2 groups by using randomisation method from online randomisation available at Statsdirect.com. Group A patients were treated using SIGN tibia solid intramedullary nails, 41 patients; Group B patients were treated by using (PITKAR) Indian Hollow intramedullary tibia nails, 31 patients; 36 patients belonged to the age group of 34 to 49 years (50\%), 22 patients to the age group of 18 to 33 years (30.55\%) and 14 belonged to the age group of 50 to 65 years $(19.44 \%)$ (Table 1). Simple fractures of shaft of Tibia were found in 56 patients and 16 patients presented with open fractures. Among the former group, 31 were in Group A and 25 in Group B. Among the Group A patients belonging to 18 - 33 were 12, belonging to 34 to 49 years were 20 and 50 to 65 were 09. In Group B patients belonging to 18 to 33 were 10 , belonging to 34 to 49 
years were 16 and 50 to 65 were 5 . Among the open fractures (16) patients belonging to 18 to 33 were 06 , belonging to 34 to 49 years were 04 and 50 to 65 were 04 . Type I Gustilo's fractures were found in 4/72 patients (5.55\%); Group A-2
(2.77\%) and Group B-2 (2.77\%), Type II in 08 patients (11.11\%), Group A 5 (6.94\%) and Group B 3 (4.16\%); type III-A in 4 (5.55\%); Group A-2 (2.77\%) and Group B-2 (2.77\%) patients (Table 1).

\begin{tabular}{|c|c|c|c|c|c|c|c|c|c|c|c|c|}
\hline \multirow{3}{*}{$\begin{array}{c}\text { Age Group - } \\
72\end{array}$} & \multirow{2}{*}{\multicolumn{2}{|c|}{$\begin{array}{c}\text { Male } \\
56\end{array}$}} & \multirow{2}{*}{\multicolumn{2}{|c|}{$\begin{array}{c}\text { Female } \\
16\end{array}$}} & \multicolumn{2}{|c|}{$\begin{array}{c}\text { Closed } \\
\text { Fractures - } 56\end{array}$} & \multicolumn{6}{|c|}{ Gustilo's Classification for Open Fractures } \\
\hline & & & & & & & Тур & I-04 & Type & II-08 & Type & II-A04 \\
\hline & A - 31 & B - 25 & A - 10 & B - 06 & A - 31 & B - 25 & A - 02 & B - 02 & A - 05 & B - 03 & A - 02 & B - 02 \\
\hline $18-33-22$ & 09 & 07 & 03 & 03 & 12 & 07 & 00 & 01 & 01 & 02 & 01 & 01 \\
\hline $34-49-36$ & 15 & 13 & 05 & 03 & 11 & 11 & 01 & 00 & 02 & 00 & 00 & 01 \\
\hline $50-65-14$ & 07 & 05 & 02 & 00 & 08 & 06 & 00 & 01 & 02 & 00 & 01 & 00 \\
\hline
\end{tabular}

Among the 72 patients, right side fracture was found in $39(54.16 \%)$ patients and the remaining $33(45.83 \%)$ on left side. Upper third fractures were found in 18 patients (25\%), middle third fractures were found in 36 patients (50\%) and the lower third fractures were found in 16 patients (22.22\%), (Table 2).

\begin{tabular}{|c|c|c|c|c|c|c|c|c|}
\hline $\begin{array}{c}\text { Observation- } \\
\text { Gender }\end{array}$ & \multicolumn{2}{|c|}{ Total- 72 } & \multicolumn{2}{c|}{ Upper Third- 18 } & \multicolumn{2}{c|}{ Middle Third- 36 } & \multicolumn{2}{c|}{ Lower Third- 16 } \\
\cline { 2 - 9 } & A - 41 & B - 31 & A & B & A & B & A & B \\
\hline Male- 56 & 30 & 26 & 08 & 06 & 16 & 14 & 06 & 06 \\
\hline Female- 16 & 11 & 05 & 03 & 01 & 04 & 02 & 04 & 02 \\
\hline Side & & & & & & & & \\
\hline Right- 39 & 21 & 18 & 07 & 04 & 11 & 10 & 03 & 06 \\
\hline Left- 33 & 20 & 13 & 06 & 05 & 12 & 07 & 02 & 02 \\
\hline
\end{tabular}

Among the 72 patients 35 patients were operated within 24 hours (48.61\%), 16 were operated within 72 hours (22.22\%), 12 were operated within 5 days (16.66\%) and 9 were operated between 6 and 10 days (12.5\%) (Table 3).

\begin{tabular}{|c|c|c|c|c|c|c|c|c|}
\hline \multirow{2}{*}{ Timing of Surgery } & \multicolumn{2}{|c|}{ Within 12 Hrs. } & \multicolumn{2}{|c|}{ Within 72 Hrs. } & \multicolumn{2}{|c|}{3 to 5 Days } & \multicolumn{2}{|c|}{6 - 10 Days } \\
\hline & A & B & A & B & A & B & A & B \\
\hline Male- 56 & & 27 & & 12 & & 09 & & 08 \\
\hline Female- 16 & & 08 & & 04 & & 03 & & 01 \\
\hline
\end{tabular}

Among the 72 patients early Superficial infection was noted in 5.55\%, Deep infection in 4.16\%, Delayed union in $1.38 \%$ of the patients (Table 4).

\begin{tabular}{|c|c|c|c|c|}
\hline Complications & Number of Patients & Percentage & Percentage \\
\hline Group & A & B & A & B \\
\hline Early Superficial Infection & 2 & 2 & 2.77 & 2.77 \\
\hline Deep Infection & 2 & 1 & 2.77 & 1.38 \\
\hline Skin necrosis without infection & 1 & 1 & 1.38 & 1.38 \\
\hline Neurovascular injury & 0 & 0 & 0 & 0 \\
\hline Compartment syndrome & 0 & 0 & 0 & 0 \\
\hline Delayed union & 0 & 1 & 0 & 1.38 \\
\hline Table 4. Showing the Complications noted in the Study Groups (n= 72)
\end{tabular}

Final results of Tibia intramedullary nailing using solid and hollow interlocking nails was assessed in both the groups and found to be Excellent in 18 of the Group A (25\%) and 15 of the Group B (20.83\%); 11 of the Group A (15.27\%) were Good and 08 of the Group B were good (11.11\%); 10 patients showed fair results in Group A (13.88\%) and 06 of the Group B (8.33\%). Poor results were observed in 2 patients of both the groups (2.77\%) (Table 5). The overall success rate was 39/41 in Group A (95.12\%) and 29/31 (93.54\%) in Group B.

\begin{tabular}{|c|c|c|c|c|c|}
\hline \multirow{2}{*}{ Final Result } & \multirow{2}{*}{ Group A- 41 } & \multirow{2}{*}{ Group B- 31 } & \multicolumn{2}{|c|}{ Overall Success Rate } & \multirow{2}{*}{ P value } \\
\cline { 3 - 5 } & & 15 & $39 / 41$ & $29 / 41$ & 0.9474 \\
\hline Excellent & 11 & 08 & $95.12 \%$ & $93.54 \%$ & - \\
\hline Good & 10 & 06 & - & $2 / 41$ & \\
\hline Fair & 02 & 02 & $2 / 41$ & Group B \\
\hline Poor & Table 5. Showing the Final Results of the Study Groups A and B (n = 72) \\
\hline
\end{tabular}


Using Chi-Square Calculator $5 \times 5$ contingency table to calculate the $\mathrm{p}$ value; was calculated using the data of end results of both the groups in this study. The Chi square statistic was 0.3646 . The $\mathrm{p}$-value was 0.9474 . The result was not significant at $\mathrm{p}<0.05$.

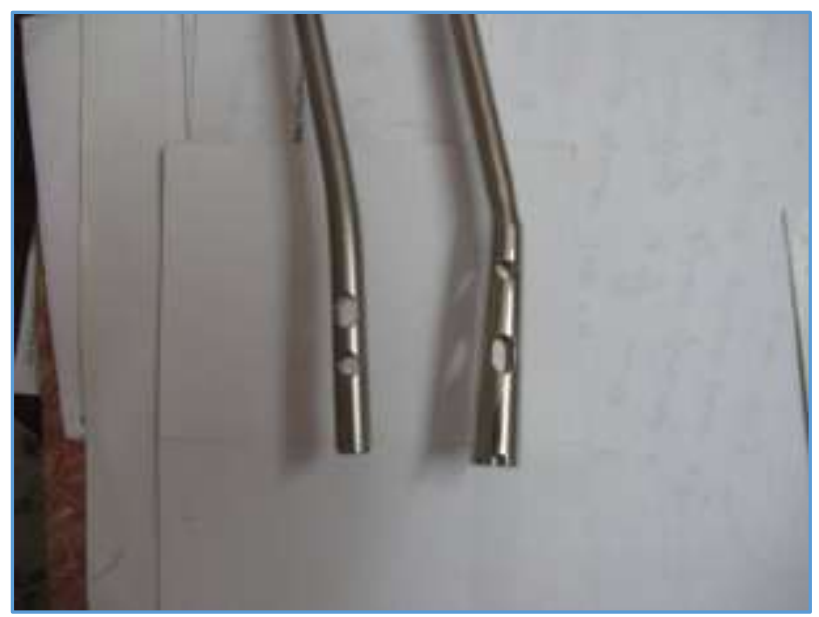

Figure 1. Showing the Proximal Ends of SIGN Nail (Left Picture) and Indian Nail (Right)

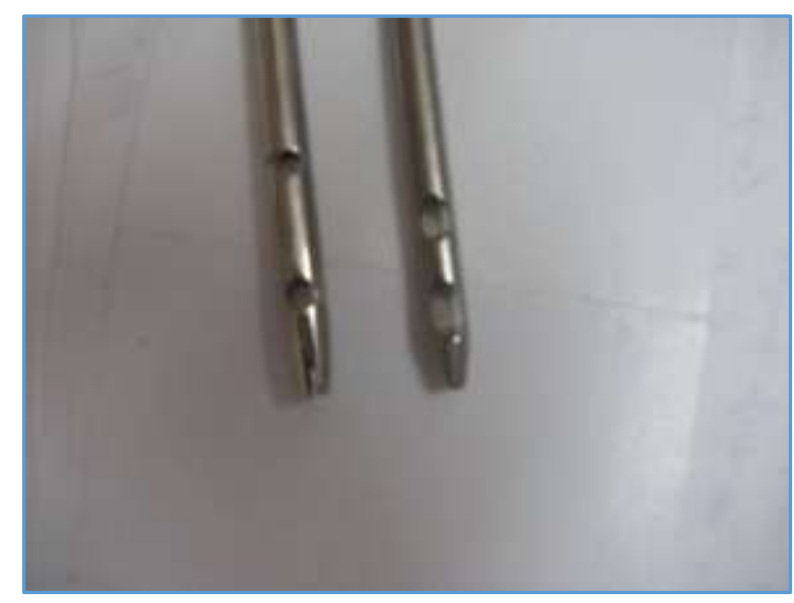

Figure 2. Showing the Distal Ends of Indian Nail (Left) and SIGN Nail (Right)

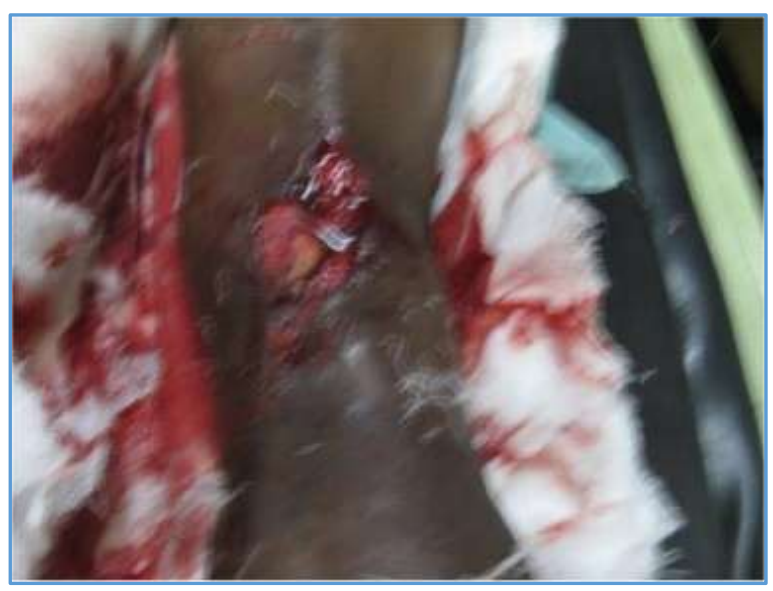

Figure 3. Showing the i. Open Fracture Shaft Tibia Left Leg, ii. X-Ray Left Leg, iii. X-Ray Right Leg A-P View, iv. X-Ray Right Leg Lateral View, v. Post-Operative X-Ray Right Leg, vi. X-Ray Left Leg, vii. Clinical Picture Postoperative

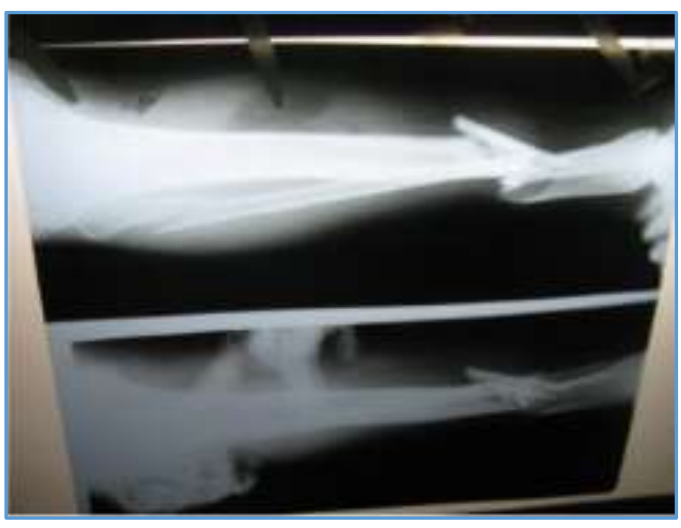

Figure 3ii

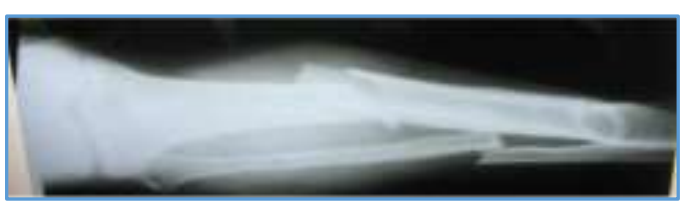

Figure 3iii

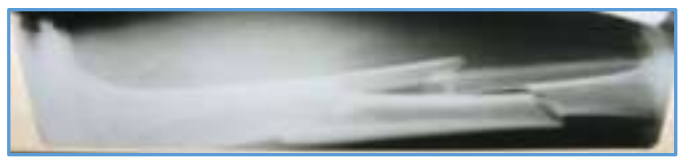

Figure 3iv

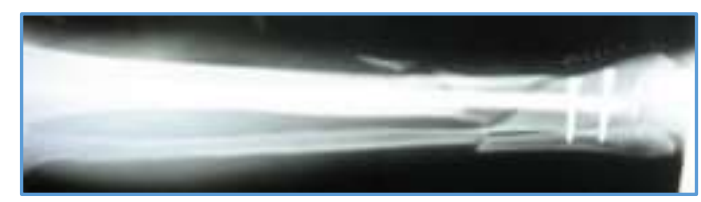

Figure 3v

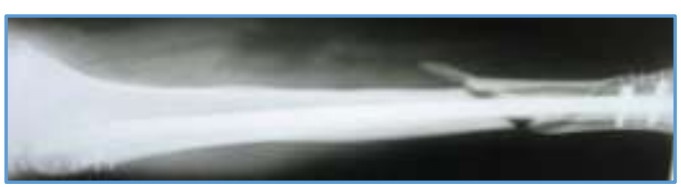

Figure 3vi

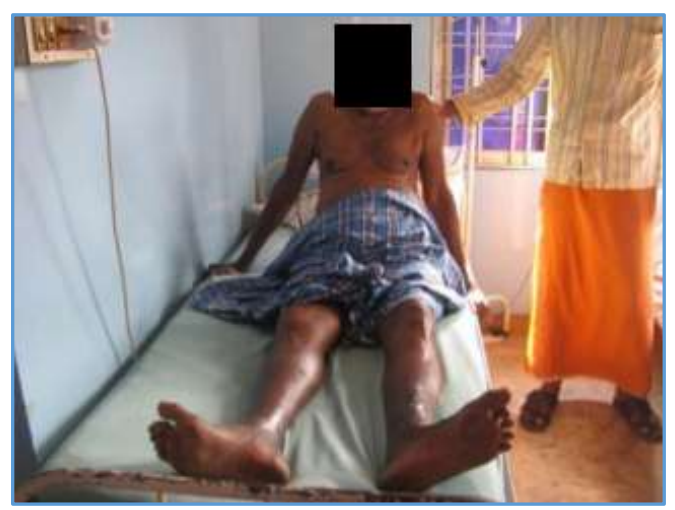

Figure 4i \& ii. Showing the Open Tibial Shaft Fracture with Wound, iii. Pre-Operative X-Ray Right Tibia A.P and Lateral Views, iv. Post-Op X-Ray Leg. v. Post-Op Clinical Picture (SIGN Nail Used) 


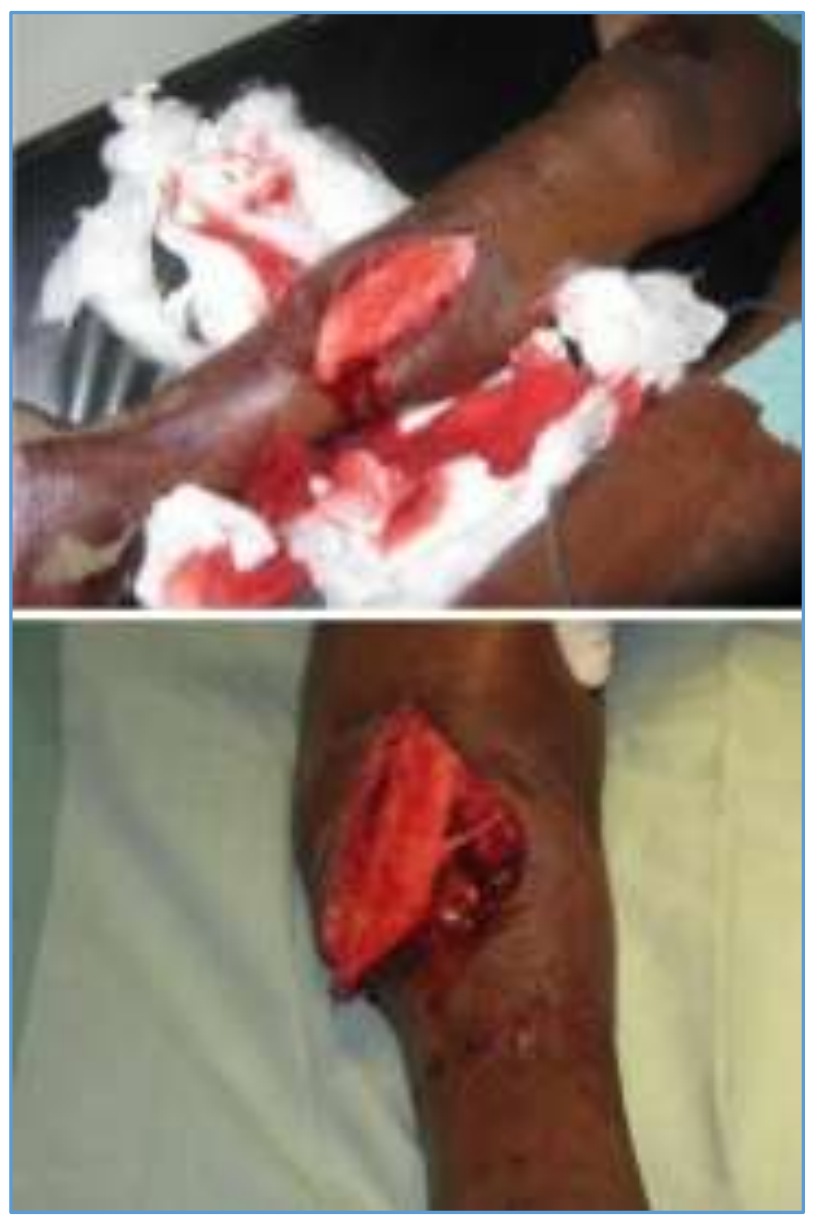

Figure 4ii \& iii

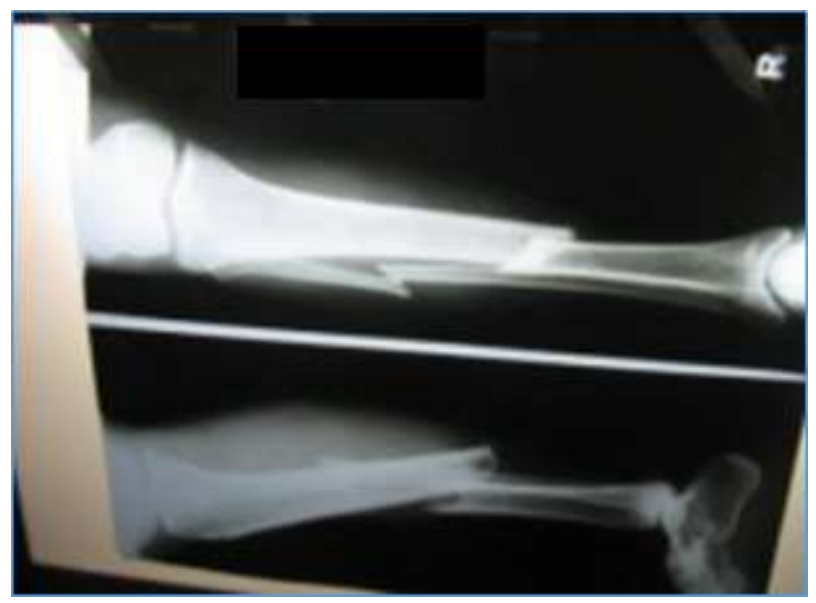

Figure 4iv

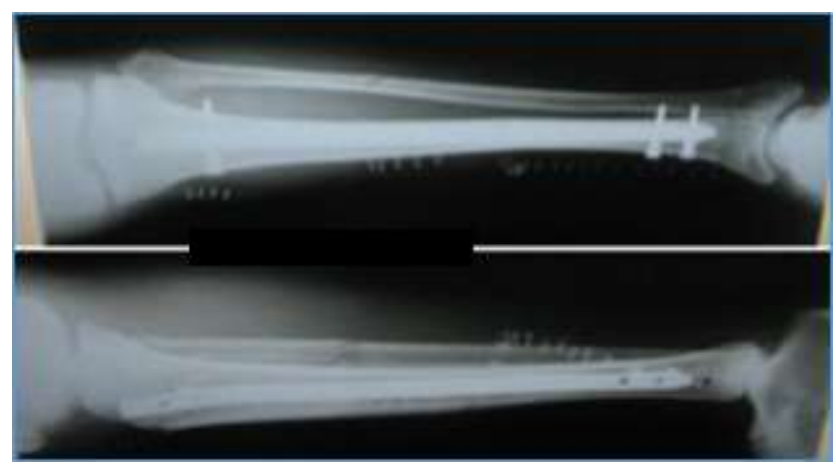

Figure 4v

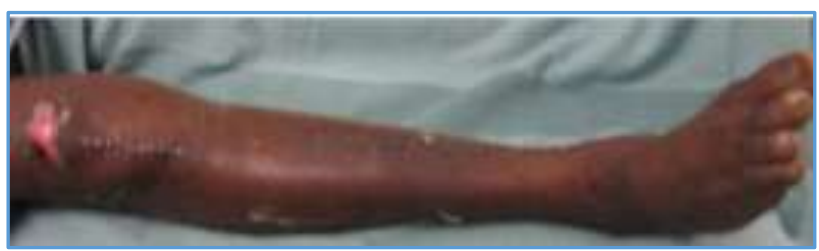

Figure 5. Showing the i. Pre-Operative X-Ray Distal Fourth Fracture, ii, iii, iv, $v$ \& vi; SIGN Nail Used; Holes Close to the End of the Nail can be Noted. Alignment and Disimpaction of Fracture with IMN In Situ is Seen
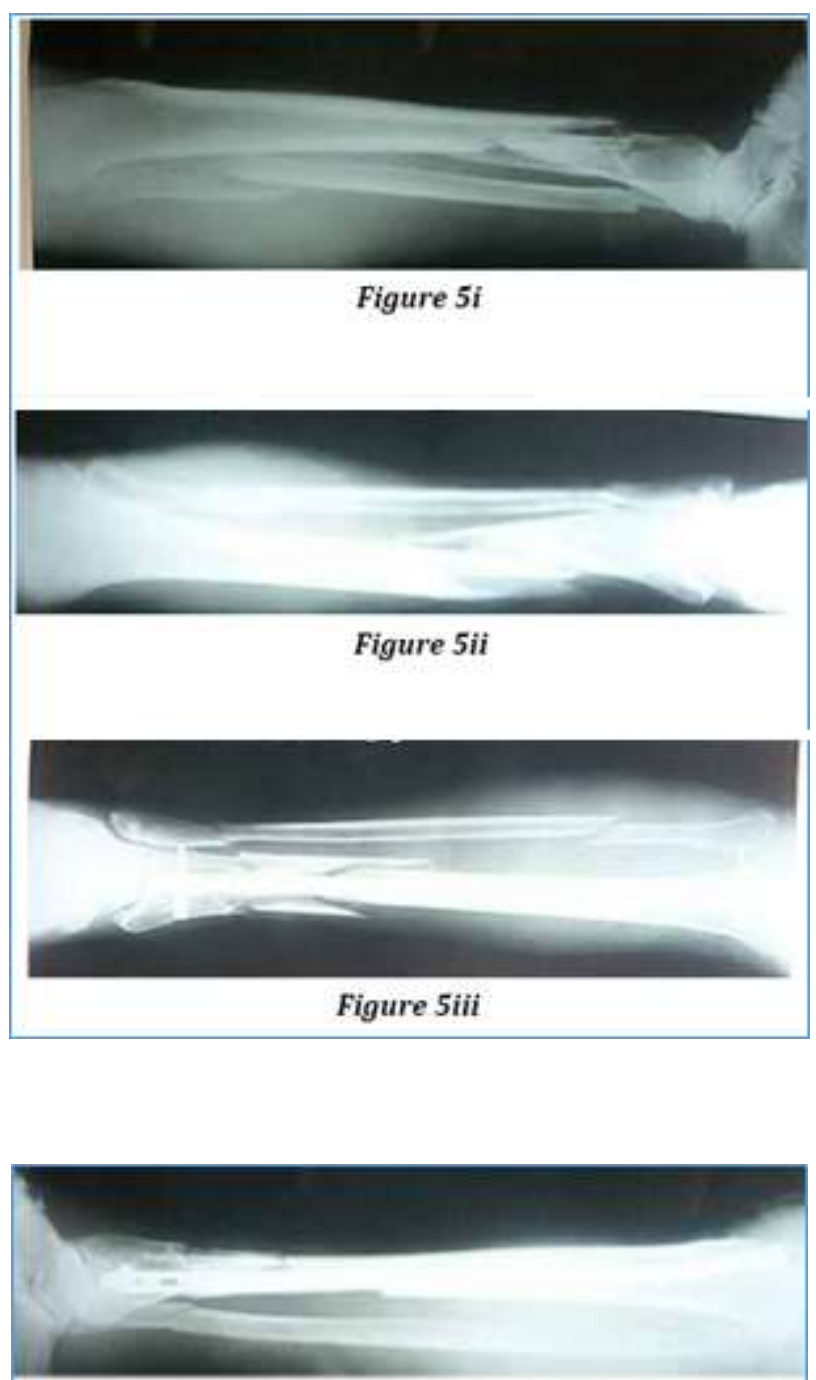

Figure 5iv

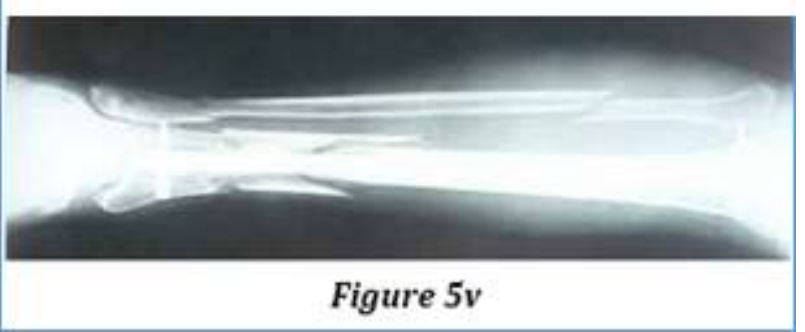




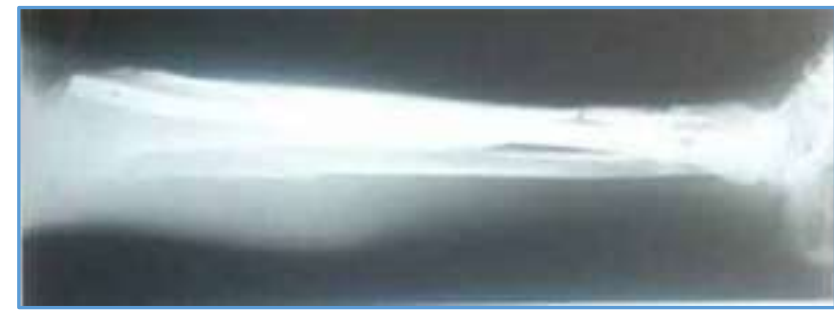

Figure 5vi. Lower $4^{\text {th }}$ Fracture 3 month Post-Operative

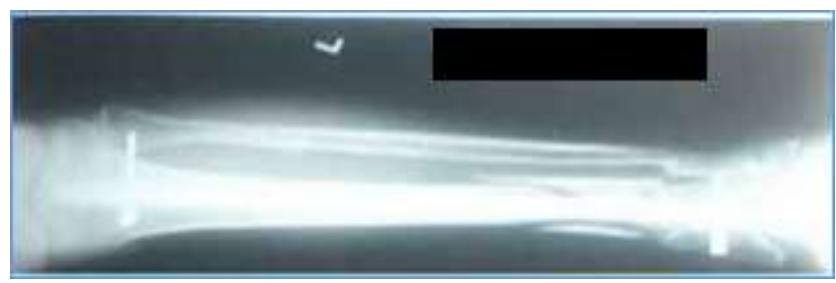

Figure 5vii. Lower $4^{\text {th }}$ Fracture 17 months Post-Operative

\section{DISCUSSION}

Fractures of Tibia are commonly encountered in Orthopaedic practice. The usual cause of fracture is direct impact during Motor Vehicle Accidents. Intramedullary nailing for the fixation of the diaphyseal fractures was introduced by G. Küntscher.(13) Across the world currently, IMN are being performed with good results. Closed IMN along with internal locking technique which is common now is desirable, which hastens biological osteosynthesis. There are proponents and opponents claiming the superiority of the reamed nail over the un-reamed technique. The present study was conducted on 72 patients and 53 patients were followed up for 2 years. Males (56) were more in number when compared to females(14) as reported in the world literature. Middle third shaft fractures of Tibia were observed in large number (36) when compared to upper(15) and lower end(14) fractures in this study. Brown et al(16) reported 98\% success among the 128 patients with Type I acute displaced open fractures with reamed nailing at an average of 17 weeks. In the present study, the overall success rates were $95.12 \%$ in Group A and 93.54\% in Group B. Using Chi-Square Calculator $5 \times 5$ contingency table to calculate the $\mathrm{p}$ value; was calculated using the data of end results of both the groups in this study. The Chi square statistic was 0.3646 . The $\mathrm{p}$-value was 0.9474 . The result was not significant at $\mathrm{p}<0.05$. The incidence of deep infection was $17.8 \%$, and the malunion rate was $2.4 \%$. Due to excellent results with un-reamed nailing with the solid tibial nail in fracture tibia led to its use as the primary method of treatment in fractures with soft tissue injury.(14) The unreamed intramedullary nailing provides a safe and effective tibial stabilisation in the acute multi-trauma patients.(17) IMN without reaming is less damaging to endosteal blood supply than nailing with reaming. In open fractures, this factor has a special importance in the treatment where outer cortical blood supply may be damaged by periosteal stripping. Reaming also produces large amount of reamed bone, which acts as a devitalised bone or microseqestra and carries an increased risk of infection. Reaming also leads to necrosis and increases chances of fat embolism. These adverse effects are avoided in an unreamed nailing.(15) In a multi-centre study comparing the results of using compression plating, intramedullary nailing and external fixators in the management of segmental fractures in UK, it was observed that IMN had the benefit of soft tissue protection, load-sharing capacity of the implant, closed method application and preservation of extramedullary blood supply. $(18,19,20)$ Another major advantage of interlocked IMN is incidence of limb shortening is less and rotational alignment is maintained.(21) To get these results in this study in 4 of patient's fractures were statistically locked with 3 to 4 interlocking screws. Delayed union and non-union are commonly known complications of segmental open fractures.(22) In the present study, only one patient had nonunion involving the middle and distal fragments of compound fracture with multiple fragments, whereas the middle and the proximal segment united within 4 months. This was managed by exchange nailing with cancellous bone grafting followed by dynamisation. The other complications such as superficial infections, necrosis without infection subsided with change of antibiotics within few days. Radiation exposure is less with SIGN nail, because both proximal and distal locking can be done using Jig without the need of $\mathrm{C}$ arm. In the case of Hollow nail, distal locking has to be done with $\mathrm{C}$ arm (Free hand technique). This is because Solid nail does not deform while insertion and so Jig can be used. In upper third fractures of Tibia, SIGN nail is preferable because the Herzog bend is gradual and of less degree $\left(9^{0}\right)$ (Fig. 1) and is situated more proximally (5 $\mathrm{cm}$ from the proximal end), whereas Indian nail has acute Herzog bend of $15^{\circ}$ (Fig. 1) and is situated $6.5 \mathrm{~cm}$ below the proximal end. In lower third fractures of Tibia SIGN is definitely better, because its distal locking slots are close to the end of the nail, just $1 \mathrm{~cm}$ from distal end. SIGN nail can even be used in lower $4^{\text {th }}$ fractures of Tibia as shown in patients in this study. Orientation of distal locking holes is anteroposterior in Indian PITKAR nail, so it is suitable in fractures with anterior and posterior fragments. SIGN nail is having mediolateral locking slots distally suitable for fractures causing medial and lateral fragments. Because SIGN nail has slots on either ends, there is no need of Dynamisation. The original fixation is in the dynamic mode. In compound fractures, SIGN nail is safer because of its solid nature, even if some infection happens; it cannot spread along the nail as can happen in hollow nail. So primary nailing can be done in more severe compound fractures like Grade 3 fractures if patient present to the hospital early (Fig. 3). This is evident from the examples of cases presented. In cases of Segmental fractures, hollow nail is preferred because of the technical advantage with it. Once the guidewire is passed, nail can be inserted easily in hollow nail. With the Solid nail, manoeuvring the nail at the two fracture sites in the tibia can be time consuming.

\section{CONCLUSION}

Intramedullary nailing for open fractures of shaft of Tibia with Solid (SIGN) or Hollow (PITKAR) nailing gives unequivocal results with identical clinical parameters used pre-operatively and post-operatively. The complication rate is lower with both the methods. It is advantageous to have interlocking nails of different designs in our armamentarium to use in different cases of shaft fractures of Tibia, since each shaft fracture is unique in its site and characteristics. 


\section{REFERENCES}

[1] Alho A, Benterud JG, Hogevold HE, et al. Comparison of functional bracing and locked intramedullary nailing in the treatment of displaced tibial shaft fractures. Clin Orthop Relat Res 1992;277:243-50.

[2] Bone LB, Johnson KD. Treatment of tibial fractures by reaming and intramedullary nailing. J Bone Joint Surg Am 1986;68(6):877-87.

[3] Brohm P, Scherer MA, Frueh HJ, et al. Experimental studies of the biomechanical properties of hollow nails and solid nails for interlocking intramedullary nailing in the dog. Biomed Tech 1995;40:24-8.

[4] Coles CP, Gross M. Closed tibial shaft fractures: management and treatment complications. A review of the prospective literature. Can J Surg 2000;43(4): 256-62.

[5] Zirkle LG. Injuries in developing countries--how can we help? The role of orthopaedic surgeons. Clin Orthop Relat Res 2008;466(10):2443-50.

[6] Henley MB. Intramedullary devices for tibial fracture stabilization. Clin Orthop 1989;240:87-96.

[7] Hooper GJ, Keddell RG, Penny ID. Conservative management or closed nailing for tibial shaft fractures. A randomized prospective trial. J Bone Joint Surg Br 1991;73(1):83-5.

[8] Schandelmaier P, Krettek C, Tscherne H. Biomechanical study of nine different tibia locking nails. J Orthop Trauma 1996;10(1):37-44.

[9] Ikem IC, Ogunlusi JD, Ine HR. Achieving interlocking nails without using an image intensifier. Int Orthop 2007;31(4):487-90.

[10] Keating JF, O'Brien PJ, Blachut PA, et al. Locking intramedullary nailing with and without reaming for open fractures of the tibial shaft: a prospective randomized study. J Bone Joint Surg Am 1997;79(3): 334-41.

[11] Keating JF, O’Brien PJ, Blachut PA, et al. Reamed interlocking intramedullary nailing of open fractures of the tibia. Clin Orthop 1997;338:182-91.
[12] Orthopaedics one articles. In: Orthopaedics One - the orthopaedic knowledge network. 2009;16:47. Last modified 2012;8:33. ver. 246.

http://www.orthopaedicsone.com/x/r4EqAQ.

[13] Donald G, Seligson D. Treatment of tibial shaft fractures by percutaneous Küntscher nailing: technical difficulties and a review of 50 consecutive cases. Clin Orthop Relat Res 1983;178:64-73.

[14] Melcher GA, Ryf C, Leutenegger A, et al. Tibial fractures treated with the AO undreamed tibial nail. Injury 1993;24(6):407-10.

[15] Singh R, Motten T, Kalsotra N, et al. Unreamed solid locked nailing in the treatment of compound diaphyseal fractures of the tibia. The Internet Journal of Orthopedic Surgery 2009;17(2).

[16] Court-Brown CM, Christie J, McQueen MM. Closed intramedullary tibial nailing: its use in closed and type 1 open fractures. J Bone Joint Surg Br 1990;72(4): 605-11.

[17] Kretek C, Schandelmaier P, Tscherne H. Unreamed interlocking nailing of the closed tibial fracture with severe soft tissue injury. Clin Orthop Relat Res 1995;315:34-47.

[18] Ikpeme JO. Intramedullary interlocking nailing for humeral fractures: experiences with the RussellTaylor humeral nail. Injury 1994;25(7):447-55.

[19] Chen AL, Joseph TN, Wolinksy PR, et al. Fixation stability of comminuted humeral shaft fractures: locked intramedullary nailing versus plate fixation. J Trauma 2002;53(4):733-7.

[20] Ingman AM, Warters DA. Locked intramedullary nailing of humeral shaft fractures. Implant design. surgical technique and clinical results. J Bone Joint Surg Br 1994;76(1):23-9.

[21] Fogerty S, Tsiridis E, Kontakis G, et al. Segmental humeral fractures: prevalence of non-union and functional outcome. J Orthop 2009;6(2):e6.

[22] Mohan D. Road traffic injuries: a stocktaking. Best Pract Res Clin Rhematol 2008;22(4):725-39. 